\title{
Effect of Antiasthmatic Medication on the Surface Roughness and Color Stability of Dental Restorative Materials
}

\author{
Elif Aydogan Ayaz ${ }^{a}$ Bora Bagis ${ }^{b}$ Sedanur Turgut ${ }^{a}$ \\ Departments of Prosthodontics, Faculty of Dentistry, ${ }^{a}$ Karadeniz Technical University, Trabzon, and \\ b İzmir Katip Çelebi University, Izmir, Turkey
}

\section{Key Words}

Asthma. Salbutamol sulfate - Dental materials .

Surface roughness . Color stability

\begin{abstract}
Objective: This study evaluated the effect of antiasthmatic medication on the surface roughness and color stability of dental restorative materials. Materials and Methods: A total of 60 disc-shaped specimens were fabricated from glass ionomer $(n=20)$, composite resin $(n=20)$ and feldspathic porcelain $(n=20)$. Each material group was randomly divided into two subgroups ( $n=10)$ : (1) control group and (2) test group. Control groups of the specimens were kept in artificial saliva. Test groups were exposed to salbutamol sulfate (Ventolin Nebules) using an inhaler machine. Surface roughness measurements were done using a profilometry and color measurements were done with digital colorimetry at baseline and after inhalation and storing in artificial saliva. A two-way analysis of variance (ANOVA) and post-hoc Fisher's least significant difference test were used to compare the change in surface roughness and color. The confidence level was set at 95\%. Results: Inhaler treatment significantly increased the surface roughness and color change of glass ionomer and composite resin materials $(p<0.05)$, while the surface roughness and color of feldspathic porcelain was not
\end{abstract}

changed after inhaler treatment ( $p>0.05)$. Conclusion: The antiasthmatic inhaler medication (salbutamol sulfate) affected the surface roughness and color of composite resin and glass ionomer restorative materials. $\quad 02013 \mathrm{~S}$. Karger AG, Basel

\section{Introduction}

Asthma is a complex chronic inflammatory disease of the lower airways that affects people of all ages (approximately 300 millions) and is characterized by variable airflow obstruction and airway hyperresponsiveness [1]. The prevalence of asthma has been increasing from $2-3 \%$ to $8-10 \%$ since the 1980 s across all ages and in both genders as reported for adults [2,3] and for children [3-5] from different parts of the world.

Salbutamol sulfate is a selective $\beta 2$ agonist that elicits fast-onset bronchodilation in reversible airway obstruction and is indicated for use in the routine management of chronic bronchospasms in adults, adolescents and children aged 4-11 years with asthma [6,7]. Salbutamol sulfate is pharmaceutically available as an oral tablet or inhaler solution with a nebulizer. It is usually administered in the inhaler form, which directly affects the bronchial smooth muscles after breathing it in through the mouth [7].

\begin{tabular}{ll}
\hline KARGER & $\begin{array}{l}\text { () 2013 S. Karger AG, Basel } \\
1011-7571 / 14 / 0231-0024 \$ 39.50 / 0 \quad \text { Karger }\end{array}$ \\
$\begin{array}{l}\text { E-Mail karger@karger.com } \\
\text { www.karger.com/mpp }\end{array}$ & $\begin{array}{l}\text { This is an Open Access article licensed under the terms of the } \\
\text { Creative Commons Attribution-NonCommercial 3.0 Un- } \\
\text { ported license (CC BY-NC) (www.karger.com/OA-license), } \\
\text { applicable to the online version of the article only. Distribu- } \\
\text { tion permitted for non-commercial purposes only. }\end{array}$
\end{tabular}

Elif Aydogan Ayaz, Phd, DDs

Faculty of Dentistry, Karadeniz Technical University

Diş Hekimliği Fakültesi, Kanuni Kampüsü

TR-61080 Trabzon (Turkey)

E-Mail aydelif@yahoo.com 
Several studies [8-10] have shown that chronic treatment with a salbutamol sulfate inhaler resulted in reduced saliva flow and a higher caries prevalence than in healthy controls [8], in a higher caries susceptibility among asthmatic children [9] and caries experience in primary and permanent teeth [10].

The use of these drugs that are inhaled through the mouth may affect the color, surface texture and surface roughness of dental restorative materials [11]. The surface roughness of a material is of considerable importance, as microorganism adhesion is a prerequisite for the colonization of these surfaces [12]. A roughened surface may promote plaque accumulation and staining. This concept is of clinical importance because smooth tooth surfaces prevent the formation of a biofilm [13, 14]. Therefore, to provide ideal surface characteristics and esthetics, restorative materials must be well finished and polished.

Tooth-colored materials have gradually enhanced the quality of esthetic restorations. A natural tooth appearance and affordability are only a few of the advantages of these esthetic materials. They have been generally used to modify the anatomy of teeth, to adjust misalignments and close diastemas for esthetic purposes to provide a toothlike structure and acceptable esthetic properties [15].

Esthetic materials that are generally used in dental clinics are resin or porcelain based. Composite resins (CRs) are the most commonly used materials in restorative dentistry. However, CRs are susceptible to the action of coloring substances, which may alter their original color and compromise esthetics [14]. For more than 100 years, dental porcelains have been used for indirect restorations, such as crowns and bridges [15]. Glass ionomer (GI) restorative materials adhesively bond to the tooth structure without requiring the removal of sound tooth structure or preconditioning the cavity for chemical adhesion, as is required with CRs [16]. They are often used in an encapsulated form, which offers a controlled powder-to-liquid mixing ratio and therefore eliminates operator-induced variability [17].

Antiasthmatic medication exerts effects on dental caries and periodontal disease [10]. However, no study has evaluated the effect of antiasthmatic drugs on the color stability and surface roughness of dental materials. The aim of this study was to investigate the effect of salbutamol sulfate inhalation on the surface roughness and discoloration of dental materials. The null hypothesis was that no significant changes in the surface roughness and color of dental restorations would occur after salbutamol sulfate inhalation.

Effect of Antiasthmatic Medication on Dental Restorative Materials

\section{Materials and Methods}

The disc-shaped specimens (10 $\mathrm{mm}$ in diameter and $2 \mathrm{~mm}$ in thickness) of GI (Ketac molar, 3M ESPE, Minnesota, Minn., USA), CR (Filtek restorative, 3M ESPE, Minnesota, Minn., USA) and feldspathic porcelain (FP; Vita Omega 900, Vita Zahnfabrik, Bad Säckingen, Germany) (shade A2) were used. GI and CR specimens were fabricated in a Teflon mold with an incremental technique. Then, specimens were light-cured for $40 \mathrm{~s}$ using a light-emitting diode device (Mini LED, Satelec Acteon Group, Merignac, France) and polished with polishing discs (Sof-Lex, 3M Dental Products, St. Paul, Minn., USA) with intermittent movements lasting $10 \mathrm{~s}$ each time. FP material (1-mm thickness of opaque porcelain and 1 -mm thickness of dentine porcelain) was fired onto the metal discs in a porcelain-firing oven (Vita Vacumat 40T, Vita Zahnfabrik) at $760^{\circ} \mathrm{C}$. Then, the overglazing liquid was applied to the surfaces and specimens were placed into the firing oven at $600^{\circ} \mathrm{C}$.

All specimens were stored in artificial saliva for $24 \mathrm{~h}$ at $37^{\circ} \mathrm{C}$ to simulate clinical conditions before measurements. Artificial saliva was prepared as previously described by Ahn et al. [18] by mixing $\mathrm{KCl}(0.4 \mathrm{~g} / \mathrm{l}), \mathrm{NaCl}(0.4 \mathrm{~g} / \mathrm{l}), \mathrm{CaCl}_{2} \cdot 2 \mathrm{H}_{2} \mathrm{O}(0.906 \mathrm{~g} / \mathrm{l}), \mathrm{NaH}_{2} \mathrm{PO}_{4} \cdot 2 \mathrm{H}_{2} \mathrm{O}$ $(0.690 \mathrm{~g} / \mathrm{l}), \mathrm{Na}_{2} \mathrm{~S} \cdot 9 \mathrm{H}_{2} \mathrm{O}(0.005 \mathrm{~g} / \mathrm{l})$ and urea $(1 \mathrm{~g} / \mathrm{l})$. Color readouts and surface roughness values of the test specimens were recorded at baseline. The specimens were then randomly divided into two groups $(\mathrm{n}=10)$. In the tested group, specimens were subjected to salbutamol sulfate (Ventolin Nebules, Glaxo Smith Kline, Boronia, Vic., Australia) using an inhaler machine (Vivocare V 5002, Bremen Limited, Hong Kong) and then kept in artificial saliva for 1 week. In the control group, specimens were also kept in artificial saliva for 1 week. During the salbutamol sulfate application, the specimens were placed into a chamber using a supporting device that would allow the samples to remain in a vertical position so that the greater part of their surface would be exposed. After exposure to each inhaler strip, the test specimens were immersed in artificial saliva, brushed with toothpaste (Colgate Total, Colgate-Palmolive, Istanbul, Turkey) and washed under running water to simulate clinical conditions; they were then exposed to the next strip. Each sample was treated with 20 $\mathrm{mg} \times 7$ nebules, as $20 \mathrm{mg}$ is the average daily dose for asthma patients.

The surface roughness values $(\mathrm{Ra})$ of the specimens were measured with a profilometer (SJ-201P, Mitutoya Corp, Kawasaki, Japan) using a 0.4-gf load for $5 \mathrm{~s}$. The resolution of the surface roughness data was $0.01 \mu \mathrm{m}$. Three readings were taken from each specimen (at the center of the specimen, $1 \mathrm{~mm}$ to the right and $1 \mathrm{~mm}$ to the left), and the mean Ra value was calculated for each specimen.

Color data were recorded using a portable colorimeter (Shade Eye-ex, Shofu, Japan) with a lightness level of 5 gray background, which was selected as a standard for color measurements. The diameter of the measurement window was $3 \mathrm{~mm}$; the illumination and light beam angle was $90^{\circ}$. Color changes were examined for each specimen based on color specifications using the CIE $\mathrm{L}^{*} \mathrm{a}^{*} \mathrm{~b}^{*}$ color space system.

The CIE L*a*b* system represents a three-dimensional color space with components of lightness (L), red-green (a) and yellowblue (b) [19]. The color differences $(\Delta \mathrm{E})$ resulting from inhalation were calculated using the following equation: $\Delta \mathrm{E}=\left[\left(\Delta \mathrm{L}^{*}\right)^{2}+\right.$ $\left.\left(\Delta \mathrm{a}^{*}\right)^{2}+\left(\Delta \mathrm{b}^{* 2}\right)\right]^{1 / 2}$ where $\Delta \mathrm{L}^{*}=\mathrm{L}_{1}-\mathrm{L}_{0}, \Delta \mathrm{a}^{*}=\mathrm{a}_{1}-\mathrm{a}_{0}$ and $\Delta \mathrm{b}^{*}=$ $\mathrm{b}_{1}-\mathrm{b}_{0} . \mathrm{L}_{0}, \mathrm{a}_{0}$ and $\mathrm{b}_{0}$ were the initial measured color data. For the control groups ( $\Delta \mathrm{E}$ control), $\mathrm{L}_{1}, \mathrm{a}_{1}$ and $\mathrm{b}_{1}$ were the measured color data of the specimens that were kept in artificial saliva and not subjected to salbutamol sulfate inhalation. For the inhaler medica- 


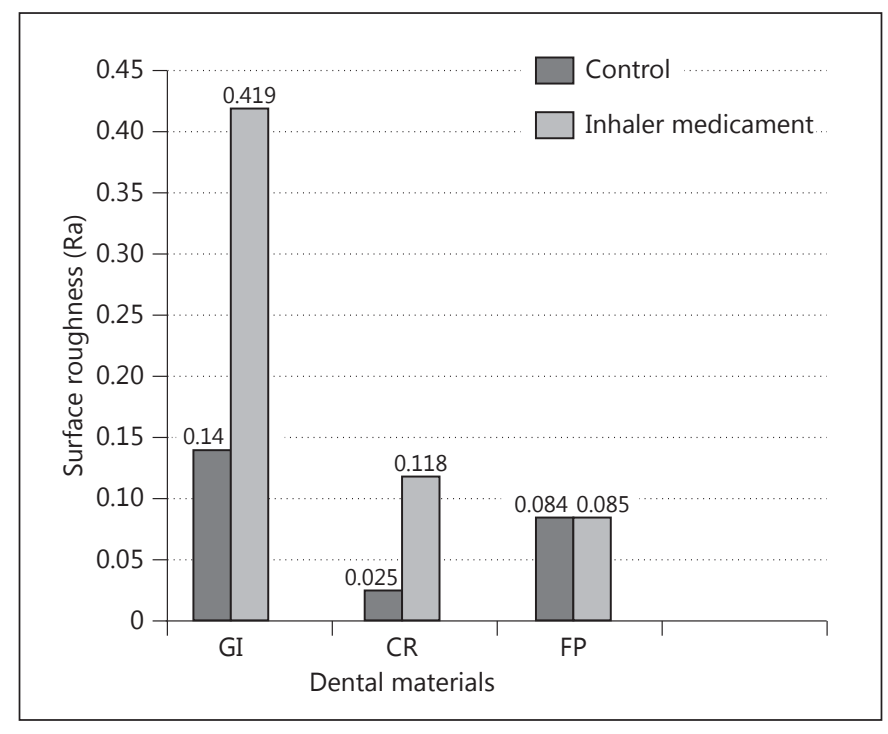

Fig. 1. Means of measured surface roughness data (Ra).

ment groups ( $\Delta \mathrm{E}$ inhaler medicament), $\mathrm{L}_{1}, \mathrm{a}_{1}$ and $\mathrm{b}_{1}$ were the measured data of the specimens that were subjected to salbutamol sulfate inhalation. All color measurements were taken from the central part of each specimen. Values of $\Delta \mathrm{E} \geq 3.3$ were considered to be clinically unacceptable [20]. To relate the color differences $(\Delta \mathrm{E})$ to the clinical environment, the color data were quantified by the National Bureau of Standards (NBS), United States units [21], with the following formula: NBS units $=\Delta \mathrm{E} \times 0.92$. Critical marks of color differences according to the NBS are classified as trace $(\mathrm{T})$ : $0.0-0.5$; slight $(\mathrm{S}): 0.5-1.5$; noticeable $(\mathrm{N}): 1.5-3.0$; appreciable $(\mathrm{A})$ : 3.0-6.0; much (M): 6.0-12.0 and very much $(\mathrm{V}):>12.0$.

\section{Statistical Analysis}

Statistical analyses were performed using the statistical package SPSS for Windows, version 15.0 (SPSS, Chicago, Ill., USA). The calculated data were tested regarding normality of the distribution using the Shapiro-Wilk test. A two-way analysis of variance (ANOVA) and post-hoc Fisher's least significant difference test were used to compare the data from each material and treatment condition. Bonferroni adjustments for pairwise differences between groups were performed. The confidence level was set at $95 \%$.

\section{Results}

The mean surface roughness values of restorative materials are presented in fig. 1. The mean $\mathrm{Ra}$ (in control groups) for GI was 0.140 , for CR 0.025 and for FP 0.084 . The mean Ra after inhaler medication for GI was 0.419 , for CR 0.118 and for FP 0.085 . Change in surface roughness for GI was 199\%, for CR 372\% and for FP 5\% (fig. 2). For the surface roughness test, the two-way interaction between restorative materials and inhaler treatment was

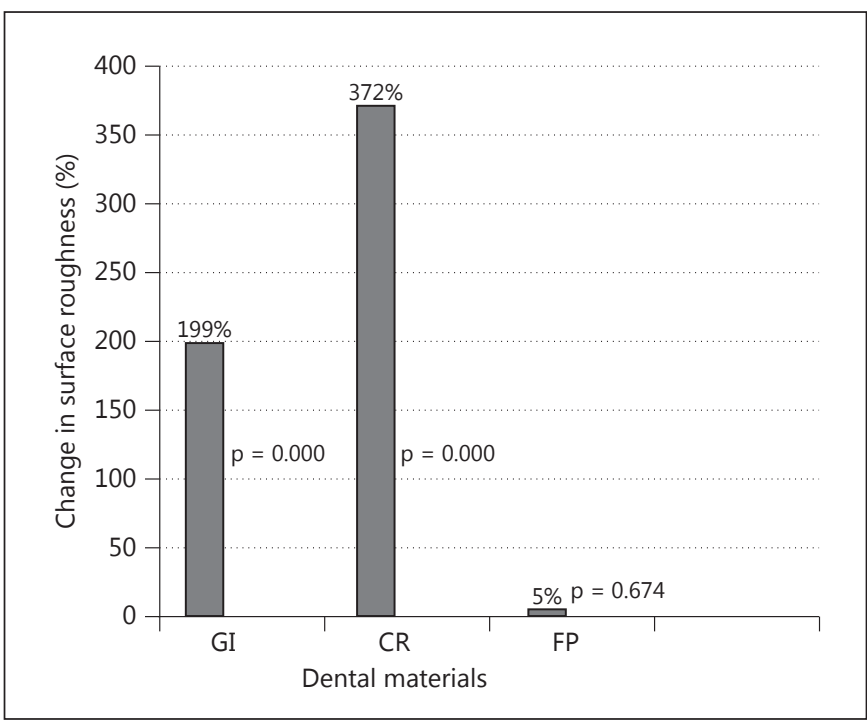

Fig. 2. Change (\%) in surface roughness.

significant $(\mathrm{p}<0.001)$. The surface roughness values of the restorative materials were significantly different both before and after inhaler treatments $(\mathrm{p}<0.05)$. Inhaler treatment significantly increased the surface roughness of GI and CR $(p<0.05)$. The surface roughness of FP was not changed significantly after inhaler treatment $(p>0.05)$.

Measured color data are presented in table 1 . The mean color changes $(\Delta \mathrm{E})$ of restorative materials are presented in fig. 3. The mean $\Delta \mathrm{E}$ (in control groups) for GI was 1.14, for CR 0.97 and for FP 0.40 . The mean $\Delta \mathrm{E}$ after inhaler medicament for GI was 6.81, for CR 6.00 and for FP 0.88 . The two-way analysis of interaction between restorative materials and inhaler treatment was significant $(\mathrm{p}<0.001)$. The smallest color change was observed in the FP group $(\mathrm{p}<0.05)$. Inhaler treatment significantly increased the $\Delta \mathrm{E}$ values of $\mathrm{GI}$ and $\mathrm{CR}(\mathrm{p}<0.05)$. The color change of FP was not significant after inhaler treatment $(p>0.05)$.

When NBS values were calculated, all restorative materials were classified as slight before inhaler treatment (GI: 1.05; CR: 0.90; FP: 0.36). FP restorations were also classified as slight after inhaler treatment (0.81). Inhaler treatment was observed to cause much color change for GI (6.27) and an appreciable change for CR (5.52) restorations.

\section{Discussion}

The null hypothesis of the study was rejected because there was a change in the surface roughness and color of GI and CR restorations after salbutamol sulfate inhalation. 
Table 1. Means of measured color data (L, a, b)

\begin{tabular}{llllllllll}
\hline & $\mathrm{L}_{0}$ & $\mathrm{~L}_{1}$ control & $\begin{array}{l}\mathrm{L}_{1} \text { inhaler } \\
\text { med }\end{array}$ & $\mathrm{a}_{0}$ & $\mathrm{a}_{1}$ control & $\begin{array}{l}\mathrm{a}_{1} \text { inhaler } \\
\text { med }\end{array}$ & $\mathrm{b}_{0}$ & $\mathrm{~b}_{1}$ control & $\begin{array}{l}\mathrm{b}_{1} \text { inhaler } \\
\text { med }\end{array}$ \\
\hline $\mathrm{GI}$ & 75.4 & 74.9 & 71.4 & 0.9 & 0.7 & 0.5 & 8.1 & 7.1 & 2.6 \\
$\mathrm{CR}$ & 77.5 & 77.3 & 72.3 & 0.4 & 0.7 & 0.3 & 8.5 & 7.6 & 5.5 \\
$\mathrm{FP}$ & 79.8 & 79.4 & 79.1 & 0.4 & 0.4 & 0.2 & 6.3 & 6.3 & 5.8 \\
\hline
\end{tabular}

$\mathrm{L}_{0}, \mathrm{a}_{0}, \mathrm{~b}_{0}=$ Initial color measurements; $\mathrm{L}_{1}, \mathrm{a}_{1}, \mathrm{~b}_{1}=$ measured color of the specimens after being subjected to only artificial saliva or subjected to salbutamol sulfate; med = medicament.

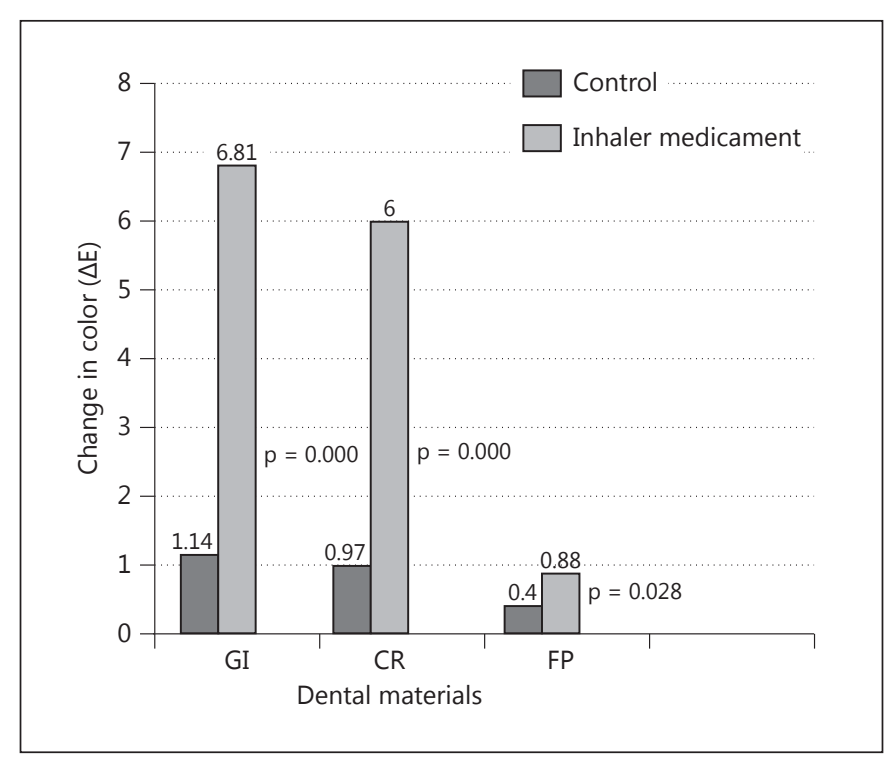

Fig. 3. Change in color $(\Delta \mathrm{E})$.

The present study showed that the inhalation of salbutamol sulfate significantly affected the surface roughness of GI and composite specimens, while that of porcelain specimens did not change. Hence the intrinsic properties and finishing procedures of restorative materials affected the surface roughness characteristic [22]. The surfaces of the porcelain specimens were finished by glazing, while the GIs and composites were not glazed but treated with the same Sof-Lex finishing and polishing discs via intraoral clinic techniques. This difference could be explained by the resistance of glazed surfaces to extrinsic factors. Another cause could have been the characteristics of the material itself. Porcelain materials do not change very much during their life in the oral cavity, but compositebased materials suffer degradation due to mechanical and/or chemical interactions with the oral environment [23]. Additionally, dental materials composed of CRs may absorb water and chemicals from the oral environment [24], which may affect the surface roughness as observed in the present study.

Like all medicines, antiasthmatic inhalers may produce some side effects. The manufacturers report that mouth or throat irritation is a common oral side effect of the drug [25]. Surface roughness is an important clinical criterion of restorative materials. Increased roughness may lead to more plaque retention, bacterial adherence and gingival irritation [12]. The results of the present study may explain the higher caries susceptibility of asthma patients undergoing treatment with inhalers and nebulizers. During the use of this medication, the drug is applied as a pressurized metered-dose aerosol unit for oral inhalation, which contains a microcrystalline suspension of albuterol sulfate ethanol and oleic acid. These substances cover the teeth and periodontal tissues during inhalation and may remain as a residue after inhalation. Thus, patients using inhalers and nebulizers should be advised to implement more precautionary oral hygiene and to have their caries activity and periodontal health status regularly examined. Generally, it is advised to wash mouth immediately after using the inhaler [6-9].

The results of the present study indicate that color change $\Delta \mathrm{E}$ values were higher in the GI and CR groups than in the FP groups. The GI and CR groups showed clinically unacceptable color changes $(\Delta \mathrm{E}>3.3)$ after inhalation. The finding confirmed the previous investigations that showed the colors of CRs and GI cements changed over time due to intrinsic or extrinsic discoloration factors $[26,27]$. Intrinsic factors generally include the chemical composition of the material, while extrinsic factors are related to the sorption of coloring agents [28]. In the current study, inhalation influenced the color of $\mathrm{CR}$ and GI restorative materials. This discoloration may possibly be due to the active ingredient of the inhaler nebule, which contains a $\left(\mathrm{C}_{13} \mathrm{H}_{21} \mathrm{NO}_{3}\right)_{2} \cdot \mathrm{H}_{2} \mathrm{SO}_{4}$ sulfate group. The ingredients of this drug may affect the sur- 
faces of the dental materials by forming a pellicle matrix that provides an acidic environment, thus promoting demineralization and increasing surface roughness and discoloration.

When the mean $\triangle \mathrm{E}$ values of the specimens were converted to NBS units, GIs exhibited much difference, CRs exhibited an appreciable difference after inhalation, while all control groups were classified as slight. The color of the porcelain specimens did not change and the difference remained slight. Samra et al. [29] evaluated the color changes of composite and porcelain restorative materials in staining solutions and reported that the smallest change was observed in the ceramic group.

Surface roughness and color properties are related to each other for dental materials because restorations with high surface roughness are more susceptible to staining [26]. Increased surface roughness causes plaque accumu- lation and discoloration of the material [30]. Additionally, the surface texture affects the color of the restoration, as a smooth surface reflects a greater amount of light than a rough surface [26].

\section{Conclusions}

The antiasthmatic inhaler medication (salbutamol sulfate) changed the surface roughness and color of CR and GI restorative materials, but it did not change these parameters in FP.

\section{Acknowledgement}

The authors thank Dr. Tamer Tuzuner for support while preparing this study.

\section{References}

1 Global Initiative for Asthma: Global strategy for asthma management and prevention: updated 2013. www.ginasthma.org/local/uploads/files/GINA_Report_March13.pdf.

- 2 Lötvall J, Ekerljung L, Rönmark EP, et al: West Sweden Asthma Study: prevalence trends over the last 18 years argues no recent increase in asthma. Respir Res 2009;10:94.

3 Khadadah M: The cost of asthma in Kuwait. Med Princ Pract 2013;22:87-91.

44 Anthracopoulos MB, Pandiora A, Fouzas S, et al: Sex-specific trends in prevalence of childhood asthma over 30 years in Patras, Greece. Acta Paediatr 2011;100:1000-1005.

5 Abal AT, Ayed A, Nair PCMG, et al: Factors responsible for asthma and rhinitis among Kuwaiti school children. Med Princ Pract 2010;19:295-298.

6 Singh S, Soni R, Rawat MK, et al: In vitro and in vivo evaluation of buccal bioadhesive films containing salbutamol sulphate. Chem Pharm Bull 2010;58:307-311.

7 Barners PJ: New therapies for chronic obstructive pulmonary disease. Med Princ Pract 2010;19:330-338.

8 Ryberg M, Möller C, Ericson T: Saliva composition and caries development in asthmatic patients treated with beta 2 -adrenoceptor agonists: a 4-year follow-up study. Scand J Dent Res 1991;99:212-218.

9 Mazzoleni S, Stellini E, Cavaleri E, et al: Dental caries in children with asthma undergoing treatment with short-acting beta2-agonists. Eur J Paediatr Dent 2008;9:132-138.

10 Samec T, Amaechi BT, Battelino T, et al: Influence of anti-asthmatic medications on dental caries in children in Slovenia. Int J Pediatr Dent 2013;23:188-196.
11 Arun Kumar A, Kumar V, Singh J, et al: Druginduced discoloration of teeth: an updated review. Clinic Pediatr 2012;51:181-185.

12 Berger JC, Driscoll CF, Romberg E, et al: Surface roughness of denture base acrylic resins after processing and polishing. J Prosthodont 2006;15:180-186.

13 Asmussen E: Factors affecting the color stability of restorative resins. Acta Odont Scan 1983;41:11-18.

14 Jin C, Nikawa H, Makihira S, et al: Changes in surface roughness and colour stability of soft denture lining materials caused by denture cleansers. J Oral Rehabil 2003;30:125-130.

15 Gordan VV, Abu-Hanna A, Mjör IA: Esthetic dentistry in North American dental schools. J Can Dent Assoc 2004;70:230.

16 Taha NA, Palamara JE, Messer HH: Assessment of laminate technique using glass ionomer and resin composite for restoration of root filled teeth. J Dent 2012;40:617-623.

17 Dowling AH, Fleming GJP: Is encapsulation of posterior glass-ionomer restoratives the solution to clinically induced variability introduced on mixing? Dent Mater 2008;24:957966.

18 Ahn HS, Kim MJ, Seol HJ, et al: Effect of $\mathrm{pH}$ and temperature on orthodontic NiTi wires immersed in acidic fluoride solution. J Biomed Mater Res B Appl Biomater 2006;79: 7-15.

19 Commission Internationale de l'Eclairage: The $\mathrm{L}^{*} \mathrm{a}^{*} \mathrm{~b}^{*}$ System. Wien, Commission Internationale de l'Eclairage, 1976, pp 10-17.

20 Fay RM, Servos T, Powers JM: Color of restorative materials after staining and bleaching. Oper Dent 1999;24:292-296.
21 Nimeroff I: Colorimetery. National Bureau of Standards Monograph 104. 1968, p 47.

22 Kern M, Thompson VP: Sandblasting and silica coating of a glass infiltrated alumina ceramic: volume loss, morphology, and changes in the surface composition. J Prosthet Dent 1994;71:453-461.

23 Heintze SD, Forjanic M, Ohmiti K, et al: Surface deterioration of dental materials after simulated toothbrushing in relation to brushing time and load. Dent Mater 2010;26:306319 .

24 Ferracane JL: Hygroscopic and hydrolytic effects in dental polymer networks. Dent Mater 2006;22:211-222.

25 Drug Information online: http://www.drugs. com/uk/ventolin_nebules_2_5mg_leaflet. html.

26 Mundim FM, Garcia LFR, Pires-De-Souza FCP: Effect of staining solutions and repolishing on color stability of direct composites. J Appl Oral Sci 2010;18:249-254.

27 Yousef M, Naga AE: Color stability of different restoratives after exposure to coloring agents. J Am Sci 2012;8:20-26.

28 Um CM, Ruyter IE: Staining of resin-based veneering materials with coffee and tea. Quintessence Int 1991;22:377-386.

29 Samra AP, Ribeiro DG, Borges CP, et al: Influence of professional prophylaxis on reducing discoloration of different aesthetic restorative materials. J Dent 2012;40:71-76.

- 30 Bollen CM, Lambrechts P, Quirynen M: Comparison of surface roughness of oral hard materials to the threshold surface roughness for bacterial plaque retention: a review of the literature. Dent Mater 1997;13:258-269. 